\title{
IMAGINÁRIO, FICÇÃO, COTIDIANO: TERMOS DA MESMA EQUAÇÃO?
}

\section{Crianças desenvolvem criatividade e espírito crítico em oficina de leitura de contos: espaço para ficção e realidade}

Na tradição oriental e em povos cuja oralidade constitui fator preponderante na cultura, ouvir e contar histórias representa uma maneira de transmissão de conhecimentos e ensinamentos. Ensinamentos que se referem não apenas à origem, desenvolvimento e organização do grupo ou povo, mas também à maneira de agir de cada indivíduo. É por meio de histórias que crianças e adultos se integram ao grupo social, assimilando usos e costumes, estabelecendo relações sociais e desenvolvendo o juízo crítico e moral.

Em algumas tribos africanas, por exemplo, quando se realiza o julgamento de um membro por uma infração cometida às normas próprias do grupo, toda a comunidade, inclusive as crianças, participa do acontecimento. Durante o julgamento, ao lado dos debates realizados para verificar-se a responsabilidade ou não do envolvido, os anciãos da tribo contam histórias. Essas histórias, ao relatarem fatos antigos, relacionados de algum modo ao que está ocorrendo no momento, subsidiam as ações dos membros do grupo e ensinam as crianças a entender e aprender os procedimentos e atitudes da comunidade.

Tal costume conjuga os termos da equação que pretendemos discutir - imaginário, ficção e cotidiano - bem como suas possíveis relações com a prática pedagógica do ato de ouvir e contar histórias, em nossa sociedade.

Quando refletimos sobre o papel do imaginário na sociedade ocidental, observamos que, sobretudo a partir do cartesianismo, o racional, o intelectual sobrepõese ao imaginário. A medida matemática $\mathrm{e}$ o método de análise constituem a base do saber, e é por meio do raciocínio, da exploração científica, de evidências analíticas que o homem pode chegar ao conheci-

\section{A AUTORA}

Alice Vieira

Professora Doutora da Faculdade de Educação da USP e Coordenadora do Laboratório da Leitura da FE-USP. Autora de O prazer do texto, também co-autora de $\mathbf{O}$ ensino de português do primeiro grau à universidade e Universos da palavra: da alfabetização à leitura. 
mento. O imaginário, o mundo dos símbolos é desprezado, relegado ao ostracismo, uma vez que não pode ser examinado e explicado científica e racionalmente'.

\section{IMAGINÁRIO E FICÇÃO}

Apenas no final do século XIX se "tomou consciência novamente da importância das imagens simbólicas na vida mental, graças à contribuição da patologia psicológica e da etnologia" ${ }^{2}$. O papel da imaginação simbólica como mecanismo de auxílio na reintegração do indivíduo ao mundo "normal" e racional decorre, de um lado, da interpretação freudiana dos sonhos e, de outro, dos estudos sobre mitos das sociedades ditas primitivas.

As investigações nas áreas da Filosofia, Sociologia e Psicologia, na primeira metade deste século, ampliaram e modificaram a visão sobre os símbolos e a imaginação. Esses já não são estudados sob o ponto de vista da patologia ou do exotismo, mas reconhece-se que o homem dá sentido à existência e ao seu mundo, por sua capacidade de simbolizar.

Os progressos nesse campo vislumbraram novas perspectivas sobre as funções exercidas pela imaginação simbólica. Entre elas, a de possibilitar o equilíbrio do homem, em diversos níveis: vital, psicossocial e antropológico. Nesse sentido, foi de capital importância a obra de Gilbert Durand ${ }^{3}$, por demonstrar, de forma decisiva, que não há ruptura entre o racional e o imaginário, e que, no processo de produção e aquisição de conhecimentos, a imaginação desempenha papel essencial.

Se no âmbito da teoria o imaginário se consolidou como elemento integrante do processo de conhecimento, o mesmo não sucede na prática.

Em alguns setores da sociedade, deparamo-nos ainda com a valorização apenas do racional, do lógico, do intelectual, como se a imaginação não fosse necessária para o desenvolvimento mental do homem, nos diversos ramos do saber.

Podemos localizar o imaginário em dois planos: o coletivo e o individual. O coletivo abrangeria o império das imagens: mitos, ritos, símbolos, devaneios, sonhos, manifestações artísticas, que se articulam e dinamizam em estruturas e esquemas. $\mathrm{O}$ individual, imerso no e derivado do coletivo próprio da civilização em que o indivíduo se insere, foi assim definido por Alain Resnais: "Uma pessoa viva é um imaginário que age (...), o cérebro

1. DURAND, Gilbert. A imaginação simbólica. São Paulo: Cultrix/EDUSP, 1988.

2. Idem. Ibidem. p.41.

3. DURAND, Gilbert. As estruturas antropológicas do imaginário. Lisboa: Editorial Presença, 1982. 
humano consegue criar novas combinações, remontar as imagens retidas na memória, e entre mil coisas, "inventar roteiros, fazer filmes""4.

Passando ao campo da literatura, e apropriando-nos das palavras de Resnais, podemos dizer que o imaginário, entre mil coisas, inventa ficção. Busquemos no dicionário etimológico as acepções de imagem, imaginário e ficção, fugindo do terreno das definições.

"IMAGEM. [Do lat. imagine] S. f. Representação, imitação, retrato; fantasma, visão, sonho, aparição; cópia, imitação (em oposição à realidade); sombra, fantasma, aparência, representação pelo pensamento, evocação, pensamento"s.

"IMAGINÁRIO. [Do lat. imaginariu] Adj. "de imagem".

"FICÇÃO. [Do lat. fictione] S. "acto de modelar", formação, criação; Figura, ato de fingir, ficção; suposição, hipótese".

Entrelaçando siginificados e limitando-nos à literatura, ficção seria o ato de criar, de modelar, de formar narrativas a partir do material presente no imaginário.

Se, de uma parte, a ficção se elabora a partir do imaginário, e se, de outra, o imaginário é a representação de imagens do real, do vivido, então ficção, imaginário e realidade tecem-se e estruturam-se mutuamente, num diálogo constante. No dizer de Held, "o autêntico imaginário não nos distancia da realidade, mas nô-la restitui, especialmente porque nos ajuda a transpor a parede do esquecimento, a tela do hábito"6.

Esteada no imaginário e na realidade, a ficção exige do leitor um acordo ficcional, que Coleridge chamou de suspensão da descrença. "O leitor tem de saber que o que está sendo narrado é uma história imaginária, mas nem por isso deve pensar que o escritor está contando mentiras. Aceitamos o acordo ficcional e fingimos que o que é narrado de fato aconteceu" ". Quando o leitor rompe o acordo ficcional e interpreta como reais fatos pertencentes ao mundo ficcional, assume, geralmente, o papel do leitor ingênuo, destruindo as fronteiras entre o real e o imaginário, realizando o que Stierle chama de leitura pragmática do texto ficcional ${ }^{8}$. Inúmeros episódios dessa natureza são relatados por Eco, em Seis passeios pelos bosques da ficção, mostrando o envolvimento de amigos e leitores com a trama narrada em Pêndulo de Foucault ${ }^{9}$.

4. Apud AVELLAR, José Carlos. Imagem e som - Imagem e ação - Imaginação. Rio de Janeiro: Paz e Terra, 1982. p. 16.

5. Todos os verbetes foram retirados de: MACHADO, José Pedro. Dicionário Etimológico da Língua Portuguesa. 3.ed. Lisboa: Livros Horizonte, 1977.

6. HELD, Jacqueline. O imaginário no poder. São Paulo: Summus, 1980. p.173.

7. ECO. Humberto. Seis passeios pelos bosques da ficção. São Paulo: Cia. das Letras, 1994. p.81.

8. STIERLE, Karlheinz. Que significa a recep̧̧ão de textos ficcionais. In: LIMA, Luís Costa. A literatura e o leitor. Rio de Janeiro: Paz e Terra, 1979.

9. ECO, Umberto. Pêndulo de Foucalt. 3.ed. Rio de Janeiro: Record, 1989. 


\section{COTIDIANO E REALIDADE}

"Todo dia ela faz tudo sempre igual", o verso de Chico Buarque, expressa com clareza o que comumente se entende por cotidiano. Algo usual, repetitivo, monótono, rotineiro, habitual. Estudos e pesquisas demonstram, no entanto, que o cotidiano não se limita ao banal, mas envolve a vida de todo homem, pois "são partes orgânicas da vida cotidiana: a organização do trabalho e da vida privada, os lazeres e o descanso, a atividade social sistematizada, o intercâmbio e a purificação" ${ }^{10}$.

Cotidiano e realidade fundem-se num mesmo plano caracterizado pela espontaneidade do agir e por motivações efêmeras que decorrem em parte do fato de o homem já nascer inserido em sua cotidianidade, assimilando as relações sociais de seu grupo.

$\mathrm{Na}$ estrutura da vida cotidiana, estabelece-se a tensão entre o particular-individual e o humano-genérico, características inerentes a todo homem. O particular-individual diz respeito às motivações individuais que possibilitam a manifestação de julgamentos e ações, segundo os usos e costumes do seu grupo social, de maneira espontânea e automática. Ao passo que o humano-genérico transcende as motivações individuais e se refere à humanidade enquanto gênero humano. Por exemplo, alimentar-se constitui uma necessidade do homem, insere-se no humano-genérico. No entanto, a escolha de determinados alimentos, a forma de prepará-los, os rituais para ingeri-los são próprios de cada comunidade e inscrevem-se no domínio do particular-individual.

Quanto mais uma civilização se distancia da vida natural, tornando-se mais complexa, isto é, quanto mais uma sociedade se afasta de situações comuns, homogêneas, criando suas necessidades, desenvolvendo-se artística e cientificamente, bem como buscando novas formas de conhecer e explicar a realidade, maiores possibilidades tem o indivíduo de romper, ainda que provisoriamente, com a cotidianidade.

A ruptura acontece quando ele questiona juízos, costumes do grupo, comparando-os com a realidade para, depois, acatá-los ou rejeitá-los, de acordo com seu julgamento.

O desenvolvimento do indivíduo resulta de suas possibilidades de libertação, na medida em que caminha do individual-particular para o humano-genérico. Ainda de acordo com Heller, os artistas e os cientistas são os que possuem maior capacidade de se afastar da particularidade e alcançarem o genérico. Nos períodos de criação ou atividade intensa, a particula-

10. HELlER, Agnes. O cotidiano e a História. Rio de Janeiro: Paz e Terra, 1992. p.18. 
ridade é mantida em suspensão, "convertendo-os em representantes do gênero humano, aparecendo como protagonistas do processo histórico global" "'. Num processo interativo, o cotidiano intervém na criação (a ação particular no genérico) ao mesmo tempo que a obra criada intervém no cotidiano (do genérico para o particular).

Nos limites deste trabalho, procuramos abordar os termos da equação: imaginário, ficção e cotidiano. Embora cada um deles seja um campo fértil para as discussões mais aprofundadas, pudemos observar a relação de igualdade válida para todos os valores das variáveis envolvidas.

\section{OFICINA DE CONTOS CLÁSSICOS}

Oficinas de leitura cujos temas giram em torno de contos de fadas, literatura infantil e juvenil, lendas, mitos e fábulas, destinadas a alunos do primeiro grau, são por nós organizadas e supervisionadas, no curso de Prática de Ensino de Português da Faculdade de Educação da USP.

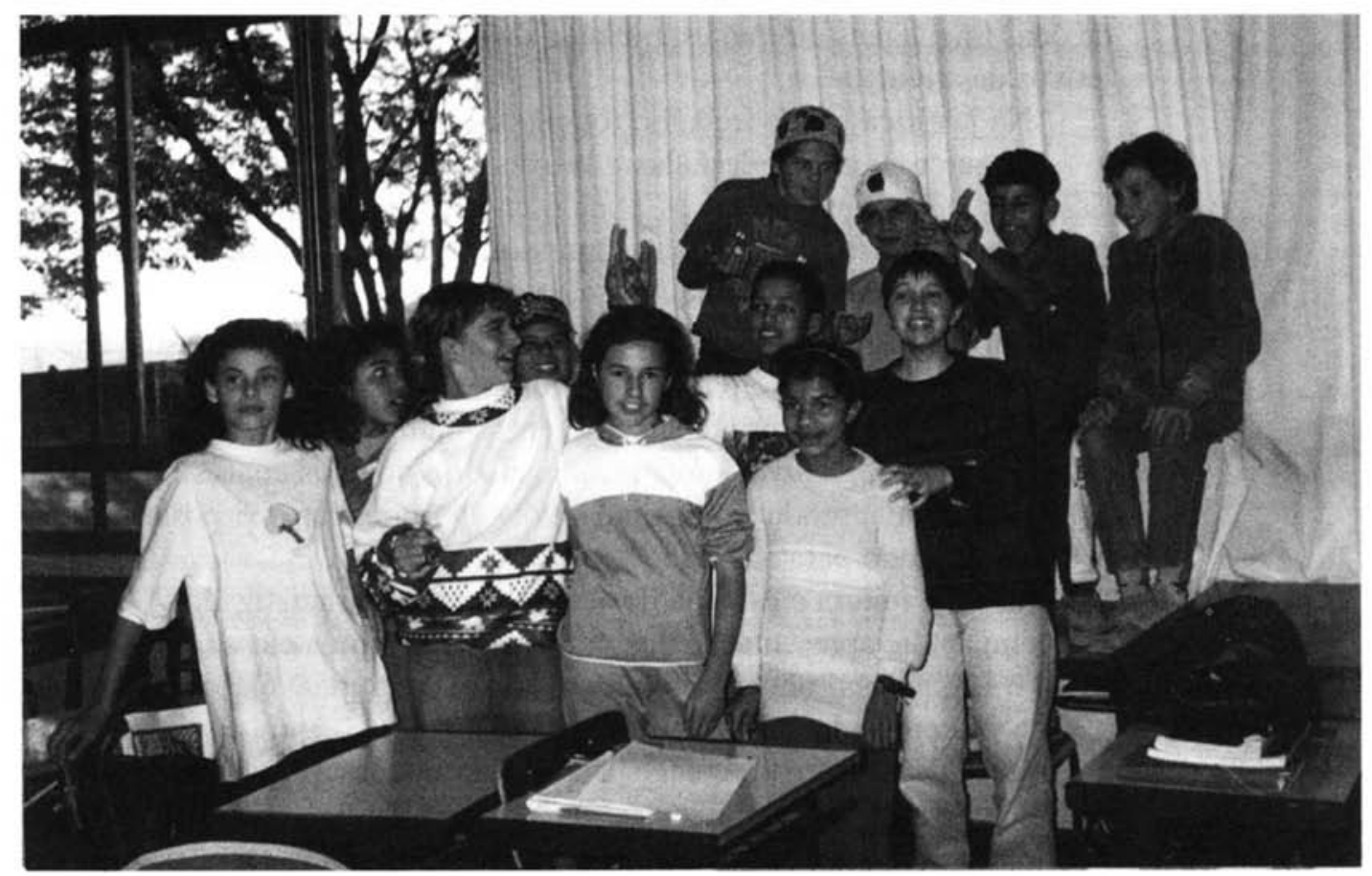

Profa. Alessandra C.R. Oliveira e os alunos da quinta série da Escola Prof. Getúlio Nogueira de Sá que trabalharam no Projeto Contos Clássicos. 
A ficção, produto do diálogo entre o imaginário e o cotidiano, é o ponto de partida para introduzir a criança ou o adolescente no mundo do sonho, do fantástico, do imaginário, alimentando sua imaginação, sensibilidade e inteligência.

As Oficinas têm também como objetivo desenvolver no aluno o gosto de ler e ouvir histórias, bem como o de produzir suas próprias narrativas.

Relataremos a seguir as atividades realizadas na Oficina de Contos Clássicos, ministrada no primeiro semestre de 1995, em uma escola de primeiro grau, na cidade de Jundiaí, no Estado de São Paulo. A Oficina foi organizada para alunos da quinta série, do período vespertino, conduzida pela professora-estagiária Alessandra Oliveira e contou com a colaboração da vice-diretora da escola, Profa. Neusa Aparecida Bizerra Sanches. Teve duração de vinte horas, distribuídas em catorze aulas.

Na elaboração do projeto, a estagiária escolheu três contos de fadas dos irmãos Grimm: Branca de Neve, A Bela Adormecida e Cinderela, e os vídeos dos mesmos contos, produzidos por Walt Disney. A comparação de duas linguagens diferentes, tratando do mesmo tema, fazia parte dos objetivos da atividade.

$\mathrm{Na}$ justificativa do trabalho foram explicitadas algumas inquietações:

O que a presença de fadas e bruxas pode significar para os alunos? Esses elementos maravilhosos podem encerrar significações mais realistas? Essas significações encontram ressonância no cotidiano dos alunos?

Apresentamos de forma resumida o projeto:

* Nas primeiras seis aulas, alternava-se a leitura de um conto, sua discussão e interpretação e a produção de um texto, com a apresentação do vídeo e discussão das principais diferenças entre as duas versões.

* Na sétima aula, houve comparação e análise dos três contos lidos.

* Na oitava aula, produção de um conto, em grupo, para ser posteriormente dramatizado para a classe.

* Nona aula, leitura e escolha dos contos a serem dramatizados.

* Décima aula, apresentação das dramatizações para a classe.

* $11^{\mathrm{a}}$ e $12^{\mathrm{a}}$, aulas produção individual de um conto para elaboração de um livro de contos de fadas.

* 13? aula, devolução dos contos pela estagiária, reescritura, quando necessária, e leitura para a classe.

* $14^{a}$ aula, dramatização dos contos para outras classes, a pedido dos colegas.

Desde o início, a classe se entusiasmou com a proposta da Oficina de Contos Clássicos. Embora a média de idade dos alunos fosse de 11 anos, muitos nunca tinham ouvido esses textos. 
Comparando-se a atividade de ouvir histórias com a de assistir aos vídeos, ficou evidente, para surpresa dos adultos, que a primeira atraiu mais.

O fato de a estagiária iniciar a aula lendo o conto na versão original, de forma dramatizada, provocou atenção e interesse. Confirmam-se, assim, as observações de Held: "É capital, entre outras, a leitura da história em voz alta. Pois é a voz do adulto que não só informa a criança quando poderá haver inquietude, mas a auxilia também, por suas entonações, a traçar a linha de demarcação entre o real e o ficcional, a apreender o humor de um texto em vez de tomá-lo 'ao pé da letra', que prepara, enfim, esse verdadeiro leitor que será capaz de uma leitura 'entrelinhas', que é a verdadeira leitura"12.

As sessões de apresentação dos vídeos foram motivadoras, entremeadas pelos risos das crianças, nas partes mais divertidas, sobretudo quando apareciam os animais da floresta e os anões. No entanto, elas relutaram, um pouco, em ler a legenda, reclamando, principalmente os meninos, das músicas ouvidas, por serem "melosas e românticas".

A predileção pelos animais, no processo de animismo infantil, teoria bem conhecida dos educadores, aflorou nas aulas, não só nos momentos em que ouviam as histórias ou assistiam, mas também nos de produção de textos. Em muitas das histórias criadas passarinhos, peixes, coelhos, lagostas, pássaros são protagonistas ou personagens secundárias. "Se o animal humanizado permite à criança, na maioria das vezes, libertar-se ao encontrar ou projetar seus desejos e temores pessoais frente à sociedade adulta organizada, é também, em muitos casos, ocasião e suporte que permite transpor, simbolicamente, certo número de situações da vida familiar, especialmente a situação de aprendizagem que sempre a fascina" 13 .

\section{SENSO CRÍTICO E CRIATIVIDADE}

Durante as discussões e comparações dos contos, muitas das crianças revelaram espírito crítico, questionando atitudes das pesonagens, por exemplo, a obediência "cega" à madrasta - as filhas da madrasta de Cinderela obedecem à mãe, cortando seus próprios calcanhares e dedões do pé, sem se rebelarem; bem como a "inteligência" do príncipe - como uma pessoa dança com outra, noites inteiras, e depois não consegue reconhecê-la?, foram alguns dos comentários ouvidos. 


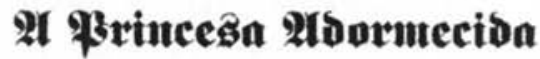
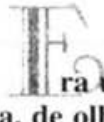
branca, de olhos verdes, elegante, rica e ambiciosa. e era a única princesa do palácio da cidade de Jordania.

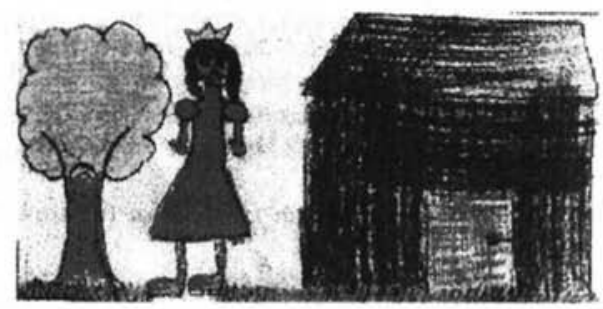

$O$ rei Rodolfo, seu pai, preparou-lhe uma grande festa de quinze anos de idade. Como era de costume, mandou preparar no salão de festas um altar para receber as seis fadas que moravam perto do palácio.

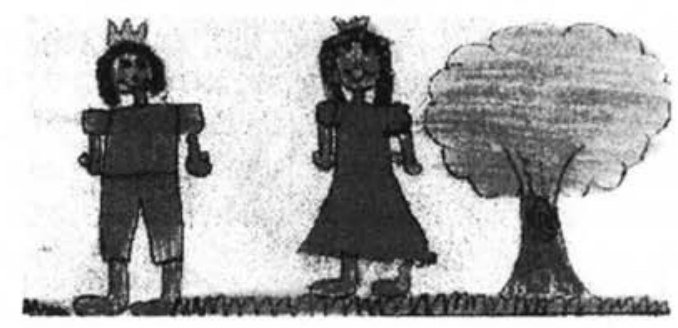

A aluna Renata Mingotti criou texto e imagem, dando dinâmica à sua história.

No decorrer da Oficina, os alunos produziam textos narrativos, a partir de estratégias diversas, expressas através de enunciados do tipo: utilizando o início do conto ouvido, criar outra história; dado o final do conto, escrever o início e o desenvolvimento; elaborar uma história que tenha o final do conto lido.

Após os debates sobre as diferenças entre os contos e os desenhos animados, as crianças escreviam seus próprios textos. Dando continuidade às atividades, na oitava aula, em duplas, os alunos criaram um conto que depois seria dramatizado, por grupos maiores.

Vida de Dondoca e A bruxa e o diabo foram os textos escolhidos pela classe. Contudo, por desacordos entre os alunos, apenas Vida de Dondoca foi representada.

Transcrevemos a seguir trechos do relatório da estagiária sobre a representação: 
"No dia da apresentação da peça Vida de Dondoca foi dado um tempo de aproximadamente $30 \mathrm{~min}$ para que eles transformassem a sala vazia em teatro. A professora-estagiária não disse nada, não deu maiores orientações quanto à execução de cenários, figurinos e mesmo sobre postura no palco. Esperava-se uma pequena peça, na mesma sala de aula, sem muitos acessórios para dramatizá-la.

"Mas foi um engano. Os alunos nos surpreenderam: trouxeram roupas e objetos(...) Organizaram também um lugar especial para a platéia, inclusive com lugares reservados para professores e direção.

“(...) Nós, professores que assistimos à apresentação, nos surpreendemos com alunos que achávamos incapazes.(...) A autoconfiança dos alunos aumentou, e todos queriam trabalhar com dramatização de novo ${ }^{14}$ ".

Comentários tornam-se desnecessários diante dos trechos transcritos. Imaginação, fantasia, gosto estético, ações pragmáticas, pensamento lógico desabrocham e florescem em contato com universos ficcionais.

A proposta de elaboração de um livro com os contos criados, individualmente, pelos alunos, para posterior publicação, inclusive com ilustrações, provocou o interesse e a motivação da classe.

A leitura das narrativas elaboradas pelos alunos permitiu-nos levantar alguns elementos que se inserem no imaginário, na ficção e no cotidiano. As crianças transitam livremente entre esses universos, criando e reunindo personagens de contos de fadas e do folclore, recriando situações apresentadas em minisséries da televisão, introduzindo conflitos familiares e aspectos religiosos, expressando medos e desejos.

Nesse mundo encantado, deparamo-nos com a bruxa que não pode andar de táxi, nem pegar carona; com um garfo chamado brubusuba e o cachimbo, chimbado; com um barraco sem tapete no chão e sem quadros na parede; com um menino que tropeçou e tirou a virilha do lugar; com a fada-madrinha dos passarinhos e com Alessandra (nome da professora-estagiária), como heroína de dois contos.

Em quase todos as histórias observamos a mediação do elemento mágico: varinha, luzinha, boneca mágica, chapéu voador, espada, espelho, estrela-falante, e de seres imaginários: sereias, magos, bruxos, estrela-fada, duendes, fadas, diabos, fantasminhas.

\section{A PRODUÇÃO DAS CRIANÇAS}

Mesmo que, estruturalmente, o texto não possa ser classificado como maravilhoso ou de fadas, há sempre a intervenção do mágico. É o que ocor- 
re em Vida de Dondoca, texto dramatizado pelos alunos, em que a trama e as personagens se assemelham aos da minissérie Scarlet.

\section{As Grimtças Gutusans}

Andréia Thomaz e felizes.

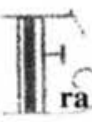
Eles ficaram sabendo que no topo do morro tinha uma bruxa muito má e eles foram lá em busca de aventuras.
Eles conseguiram chegar até lá. Mas na volta, Júlia foi picada por um escorpião. Os meninos correram chamar a bruxa e ela fez uma porção de ingredientes e deu para a menina tomar.

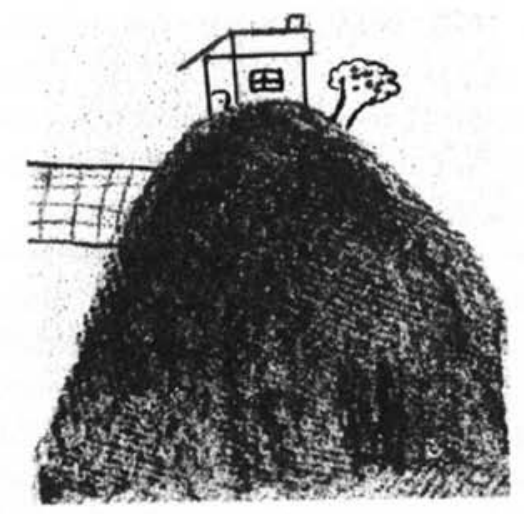

Júlia tomou e conseguiu andar até sua casa.

Então ficaram sabendo que ela era uma fada boa. Então todos foram morar juntos e viveram felizes para sempre.

\section{Jiint}

Andréia Thomaz e sua casinha na montanha: sonhos de felicidade.

Nele a personagem e a situação se transformam pela ação das estrelas.

"Rezando pela primeira vez, sentiu que não estava sozinha. De repente apareceram três estrelas no céu, sendo que estava claro, e cada vez que as estrelas se proximavam de Larissa, o céu escurecia. Até que ouviu uma voz bem baixinha:

- Psiu, psiu! Se você quiser ser o que era antes, precisa ter coragem e deixar de ser dona do seu nariz." (Vida de Dondoca)

A união do elemento mágico com a religião, necessidade de fé, de coragem, de esperança estão presentes em vários textos.

"Um dia Edna estava rezando quando apareceu uma luzinha na sua frente e falou: 
- Se você quiser melhorar sua vida, fale alguns desejos para mim e eu os realizarei. Só que eles não irão durar a vida inteira." (A Vida de Edna, de William Mezzalira)

"Depois o diabo não quis deixar Cinderela ir embora. Cinderela falou:

- Ai, como eu queria ir embora daqui.

Quando ela acabou de falar, apareceu uma fada e falou:

- Cinderela, se você quiser voltar para sua casa, não poderá mais perder a fé.

E a fada a levou do inferno para sua casa".(Cinderela e o Diabo, de Thiago Mingotti)

"O pai de Gasparzinho chorou com tristeza.

E de repente surgiu do céu uma linda fada.

Ela disse para o pai do fantasminha:

- Ricardo, não chore. Você conseguirá o que quer. Mas terá que ter coragem e acreditar em mim." (Gasparzinho, de Fabiana de Oliveira Dias)

A fascinação pela língua, o jogo com palavras, o poder encantatório das palavras estão presentes no conto $\mathbf{O}$ feitiço virou contra $\mathbf{o}$ feiticeiro. No planeta Zung Lândia, o bruxo Vulkélio II, aterrorizante e destruidor, com seu chapéu voador, é vencido pela astúcia e esperteza de Dora. Ela, depois de viajar em sua nave pelos planetas de nuvem e de sorvete, conhece um duende que a ajuda.

"Então Dora pediu para o duende soltar todos. E o duende soltou.

Vulkélio, esperto, estava para partir com seu chapéu voador.

Então Dora e o duende pegaram o chapéu e jogaram nas profundezas do vulcão.

$\mathrm{O}$ duende fez uma mágica e levou todos de novo para a Zung Lândia.

Enquanto isso, o planeta em forma de vulcão entrou em erupção e matou Vulkélio." (O feitiço virou contra o feiticeiro, de Milena Z.Bardi)

Em busca da felicidade aborda com intensidade conflitos familiares, mostrando a rejeição, a violência e a morte. Situações que geram anseio pela liberdade, concretizado pela fuga da casa paterna. Rosa, a heroína, após inúmeras peripécias, consegue finalmente, com a ajuda de uma fada, encontrar o amor e ser feliz para sempre.

"O pai de Rosa não gostava de sua esposa Sara. Um dia Scar pôs veneno no café de Sara e, então, ela morreu. 
Rosa não se conformava com a morte da mãe e então passou a morar só ela com o pai.

Um dia Scar conheceu uma feiticeira que se chamava Morgana e se casou com ela.

Quando Scar apresentou Morgana para Rosa, ela começou a gritar:

- Eu não fico com essa bruxa em casa, eu vou arrumar minha mala e vou embora!

Scar deu um tapa na cara de Rosa e disse:

- Nunca gostei mesmo de você. Só a criei por causa de sua mãe, que gostava muito de você. Mas, já que vai embora, vá e não volte nunca mais." (Em busca da felicidade, de Thalita Jacobs Buzati)

Nesta viagem panorâmica, os textos produzidos pelos alunos revelam a procura obstinada pela felicidade, o desejo de solucionar problemas existenciais, bem como a vontade imensa de viver. Aspirações plenamente atendidas por textos ficcionais que trabalham com o sonho, a fantasia e o imaginário, entre os quais os contos de fadas se destacam por constituírem modelos culturais do imaginário coletivo.

Resumo: A Oficina de Contos Clássicos para leitura de contos de fadas, literatura infantojuvenil, lendas, mitos e fábulas desenvolve trabalho pedagógico com crianças e jovens do primeiro grau em escolas da rede pública. Através da reflexão teórica sobre essa prática, a autora mostra as inter-relaçōes existentes entre imaginário, ficção e cotidiano. Apresenta alguns textos de grupos de alunos.

Palavras-chave: cotidiano, imaginário, ficção, leitura, Oficina de contos clássicos
Abstract: The Workshop of Classical Tales for reading fairy tales, infant-juvenile literature, folk-tales, myths and fables promotes pedagogical work with children and adolescents of elementary public schools. Through theoretical thought on this experience the author discussed the existing connection between imaginary, fiction and everyday reality. He presents some texts written by groups of students.

Key-words: everyday life, imaginary, fiction, reading, Workshop of Classical Tales 